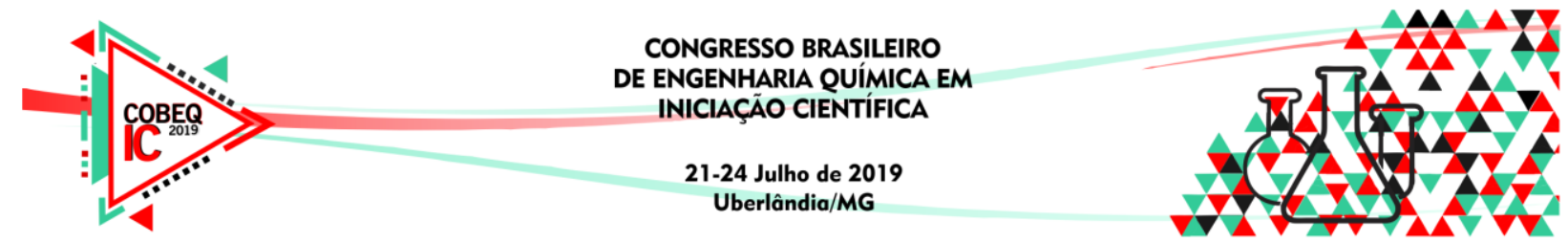

\title{
AVALIAÇÃO DO EFEITO DO pH NA ADSORÇÃO DE PROTEÍNAS DO LEITE EM BAGAÇO DE CANA-DE- AÇÚCAR
}

\author{
M. G. MORIMOTO ${ }^{1}$, M. S. FERREIRA ${ }^{1}$, L. L. ROMANIELO ${ }^{1}$ \\ ${ }^{1}$ Universidade Federal de Uberlândia, Faculdade de Engenharia Química \\ E-mail para contato: murilo_g@hotmail.com; lucienne@ufu.br
}

RESUMO - A adsorção é uma operação que tem como finalidade separar compostos químicos, nessa operação existe o enriquecimento de um componente químico (adsorvato) na região superficial de outro material (adsorvente). Por apresentar grande disponibilidade e elevada área superficial o bagaço de cana-de-açúcar vem ganhando espaço como adsorvente. O soro do leite é um resíduo proveniente do beneficiamento do leite e apesar de ser uma mistura rica em proteínas é um recurso pouco aproveitado. Esse trabalho tem como objetivo compreender o efeito do $\mathrm{pH}$ da solução sobre a capacidade de adsorver as proteínas presentes no soro do leite utilizando o bagaço de cana-de-açúcar como adsorvente. Nesse trabalho uma solução de Whey Protein - PROSTAR 100\% foi utilizada para simular o soro do leite e as soluções tampão utilizadas foram feitas com ácido cítrico e citrato de sódio nos valores de $\mathrm{pH}$ $4 ; 4,5 ; 5 ; 5,5$. Os resultados demonstraram que o $\mathrm{pH}$ influencia na operação de adsorção sendo, portanto, uma variável fundamental para a operação.

\section{INTRODUÇÃO}

A operação de adsorção é uma prática comum nas fábricas, tendo como objetivo a purificação e separação de componentes químicos. A adsorção possui alta seletividade e um consumo energético baixo (RUTHVEN, 1984). Atualmente, existe o interesse na utilização de adsorventes renováveis e baratos e é nesse cenário em que os bioadsorventes se mostram financeiramente viáveis para as operações de adsorção. A cana-de-açúcar é o maior subproduto da indústria sucroalcooléira, no ano de 2017 foram produzidas cerca de 208 milhões de toneladas de bagaço, sendo que parte desse produto foi utilizado na cogeração de energia dentro das próprias usinas. $\mathrm{O}$ bagaço também pode ser utilizado na complementação alimentar de ruminantes, entretanto deve ser complementado com um suplemento alimentar rico em proteínas. Esse estudo, tem como objetivo dar continuidade aos estudos iniciados por Ferreira (2018) estudando como o pH influência na operação de adsorção de proteínas. A determinação com acurácia da quantidade adsorvida de um soluto presente em solução em fase líquida é bastante complexa. A grande maioria dos trabalhos reportados na literatura utiliza a seguinte equação:

$Q=(\mathrm{Co}-\mathrm{Ce}) \cdot \frac{\mathrm{V}}{\mathrm{m}}$

Na qual $Q$ é quantidade de soluto adsorvida, expressa em termos da quantidade de soluto adsorvida/massa de adsorvente; $C o$ e $C e$ são a concentração do soluto na solução antes da adsorção e após atingir o equilíbrio, respectivamente; $V$ é o volume inicial da solução e $m$ é 


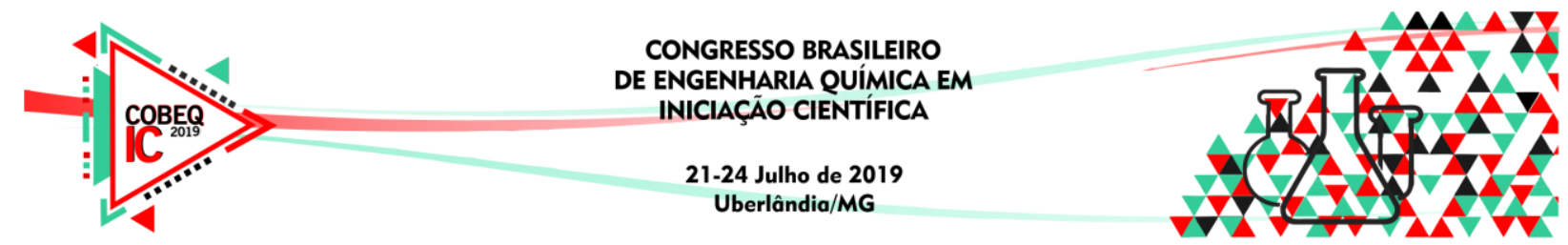

a massa de adsorvente utilizada. No entanto, é importante ressaltar que para o uso desta equação implica a suposição de algumas hipóteses, que nem sempre são justificadas. Estas hipóteses são: a) - No processo, o solvente não é adsorvido em nenhuma extensão; b) - a quantidade de soluto adsorvida é suficientemente pequena pra que não haja mudança no volume da solução. Assim, é necessário que ambas as hipóteses sejam atendidas para que o volume do sistema se mantenha constante durante todo o experimento. Porém, em geral, estas hipóteses não podem ser validadas. Mohan et al. (2014), quando estudando a adsorção da proteína albumina do soro bovino (BSA) presente em soluções aquosa, em filmes de celulose reportam que a quantidade de água adsorvida representa cerca de $92 \%$ da massa total adsorvida. Importante ressaltar, portanto, que a adsorção de quantidades apreciáveis de água causará uma redução no volume total da solução, podendo levar a concentrações do soluto em equilíbrio (após adsorção) maiores que a concentração inicial, e consequentemente, pelo uso da equação 1 haverá quantidades adsorvidas negativas. Portanto, diferentes técnicas de experimentais devem ser utilizadas para se avaliar a adsorção de solutos presentes em soluções líquidas.

\section{MATERIAIS E MÉTODOS}

\subsection{Materiais}

O bagaço de cana usado como adsorvente foi doado por estabelecimento local na região do Santa Mônica, Uberlândia, Minas Gerais. O adsorvato foi preparado a partir de Whey Protein de chocolate da marca PROSTAR 100\%, produzido pela Ultimate Nutrition com concentração inicial por volta de $0,5 \mathrm{mg}$ de proteína $/ \mathrm{mL}$. As soluções tampão utilizadas nesse trabalho foram confeccionadas a partir de ácido cítrico da marca Vetec e citrato de sódio da marca CAAL. O reagente de Bradford (utilizado na quantificação de proteínas) foi confeccionado conforme metodologia proposta por Bradford em 1976.

\subsection{Pré-Tratamento do bagaço de cana}

O bagaço foi levado com água em abundância com a finalidade de retirada de materiais indesejados, depois de lavado o bagaço seguiu para estufa onde ficou por três dias em $50^{\circ} \mathrm{C}$. Uma vez seco, o bagaço foi dividido de acordo com suas características morfológicas (fibra e medula). Após a divisão uma parte do material foi triturado em liquidificador e posteriormente foi moído. A Figura 1 mostra as duas regiões morfológicas do bagaço de cana após o pré-tratamento.

Figura 1 - Diferentes aspectos do bagaço. "A” Região medular. "B” Região fibrosa.

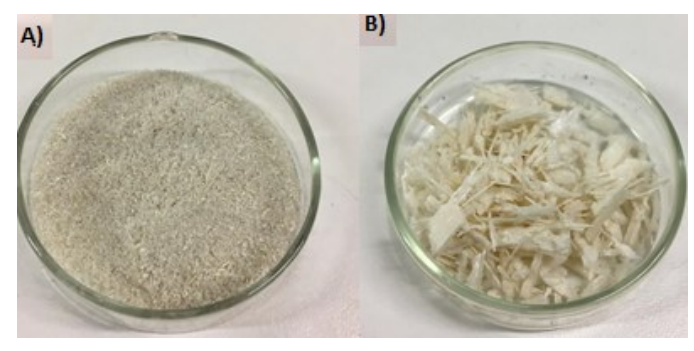




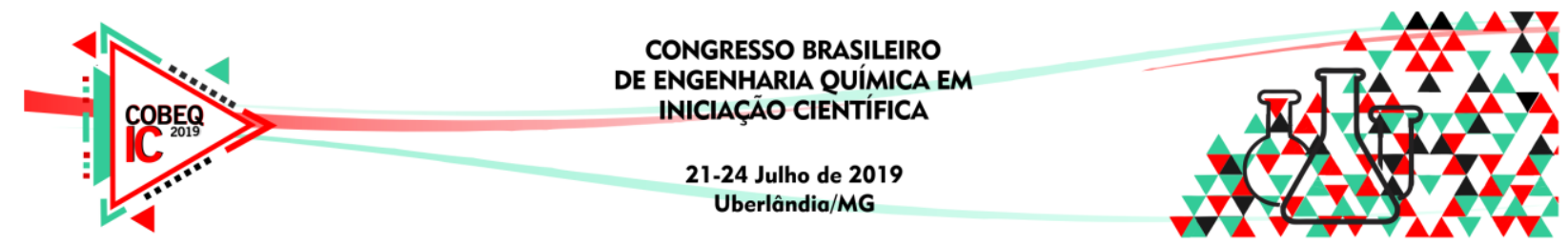

\subsection{Procedimento experimental}

Os experimentos foram realizados utilizando a parte fibrosa e medular da cana e seguiram os seguintes passos.

1. No reator, foram solubilizados $10 \mathrm{mg}$ de Whey em $20 \mathrm{~mL}$ de solução tampão;

2. Foram adicionados $300 \mathrm{mg}$ de bagaço de cana;

3. O sistema foi agitado por 6 horas em $400 \mathrm{rpm}$;

4. O sistema foi então filtrado;

5. A fase sólida foi guardada em estufa por 2 dias a $50^{\circ} \mathrm{C}$

6. Foram realizadas análises utilizando um espectrofotômetro utilizando a parte líquida;

\subsection{Quantificação}

Embora, como apresentado na introdução, o uso da equação 1 apresente limitações severas, a mesma foi utilizada para quantificar a adsorção de whey-protein. Assim, é necessário fazer uso de uma técnica para determinação da concentração de proteínas totais presentes na solução de whey-protein antes e após adsorção. Existem alguns métodos de determinação de proteínas totais via espectrometria. Zaia et al. (1998) apresentam e discutem vantagens e desvantagens de cada método. Neste trabalho, utilizou-se o método proposto por Bradford, 1976. Assim, para cada pH estudado foi construída uma curva de calibração, a qual correlaciona a leitura de absorbância da solução, em comprimento de onda de $595 \mathrm{~nm}$, com a concentração de proteína.

\subsection{Análise termogravimétrica (ATG)}

Considerando, todas as incertezas envolvidas, na consideração de que o volume da solução se mantém constante, associadas, as incertezas associadas ao método de detecção de proteínas, foram realizadas análises termogravimétricas das amostras sólidas de bagaço de cana antes e após as operações de adsorção e no Whey Protein. Os ensaios foram conduzidos utilizando um fluxo de $81 \mathrm{~mL} / \mathrm{min}(9,7 \mathrm{~mL} / \mathrm{min}$ de ar sintético e $72 \mathrm{~mL} / \mathrm{min}$ de $\mathrm{He})$ com uma rampa de aquecimento de $10^{\circ} \mathrm{C} / \mathrm{min}$.

\section{RESULTADOS E DISCUSSÃO}

\subsection{Curvas de calibração}

As curvas de calibração obtidas para esse trabalho são representas da Figura 2.

Figura 2 - Curvas de calibração.

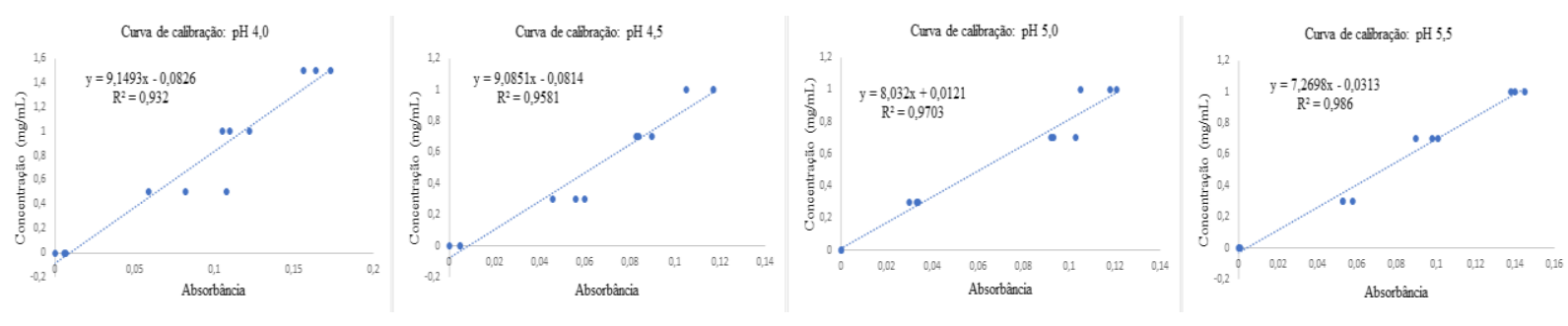




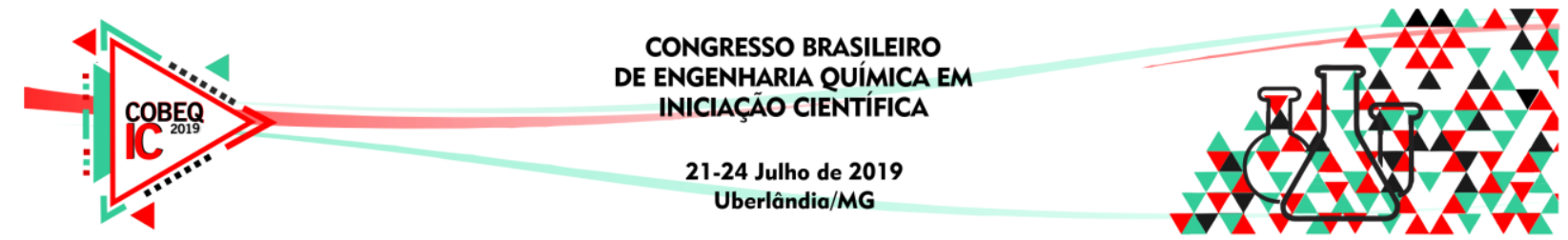

Como pode ser observado na Figura 2, o método de Bradford é bastante sensível, levando uma incerteza considerável no valor de concentração. Além disto, em cada $\mathrm{pH}$ se obtém uma curva de calibração diferente, que está associado ao fato de que proteínas assumem conformações diferentes em cada $\mathrm{pH}$ e portanto, absorvem/refletem um certo comprimento de onda com diferentes intensidades.

\subsection{Ensaios de adsorção - medula}

Os resultados obtidos são mostrados na Tabela 1.

Tabela 1 - Resultado dos ensaios de adsorção da região medular.

\begin{tabular}{|c|c|c|c|c|c|c|}
\hline $\mathrm{pH}$ & $\begin{array}{c}\text { Absorbância } \\
\text { média }\end{array}$ & $\begin{array}{c}\text { Concentração } \\
\text { inicial } \\
(\mathrm{mg} / \mathrm{mL})\end{array}$ & $\begin{array}{c}\text { Concentração } \\
\text { final }(\mathrm{mg} / \mathrm{mL})\end{array}$ & $\begin{array}{c}\text { Quantidade } \\
\text { adsorvida } \\
(\mathrm{mg} / \mathrm{mg})\end{array}$ & $\mathrm{pH}$ antes & $\mathrm{pH}$ após \\
\hline 4 & 0,062 & 0,4455 & 0,4818 & $-0,00242$ & 4,15 & 4,11 \\
\hline 4,5 & 0,034 & 0,6103 & 0,2274 & 0,02552 & 4,72 & 4,72 \\
\hline 5 & 0,0835 & 0,5769 & 0,6827 & $-0,007053$ & 5,17 & 5,22 \\
\hline 5,5 & 0,083 & 0,4145 & 0,572 & $-0,0105$ & 5,7 & 5,67 \\
\hline
\end{tabular}

Com exceção do ensaio de $\mathrm{pH} 4,5$, todos os ensaios tiveram suas concentrações finais aumentadas, isso é explicado pelo fato do adsorvato ter adsorvido água durante a operação.

\subsection{Ensaios de adsorção - fibra}

Os resultados obtidos são mostrados na tabela 2 .

Tabela 2 - Resultados dos ensaios de adsorção - região fibrosa.

\begin{tabular}{|c|c|c|c|c|}
\hline $\mathrm{pH}$ & $\begin{array}{c}\text { Absorbância } \\
\text { média }\end{array}$ & $\begin{array}{c}\text { Concentração } \\
\text { inicial } \\
(\mathrm{mg} / \mathrm{mL})\end{array}$ & $\begin{array}{c}\text { Concentração } \\
\text { final }(\mathrm{mg} / \mathrm{mL})\end{array}$ & $\begin{array}{c}\text { Quantidade } \\
\text { adsorvida }\end{array}$ \\
\hline 4 & 0,05633 & 0,4083 & 0,4327 & $-0,001627$ \\
\hline 4,5 & 0,0355 & 0,4042 & 0,2411 & 0,01087 \\
\hline 5 & 0,065 & 0,425 & 0,5342 & $-0,00728$ \\
\hline 5,5 & 0,04033 & 0,4208 & 0,2618 & 0,0106 \\
\hline
\end{tabular}

Podemos concluir que para os ensaios utilizando a fibra do bagaço houve menor quantidade de água adsorvida isso é evidenciado pelos valores de quantidade adsorvida serem em sua maior parte positivos.

\subsection{Análises termogravimétricas}

A Figura 3 mostra os resultados para o bagaço de cana (fibra e medula) antes do processo de adsorção e para o Whey Protein. 


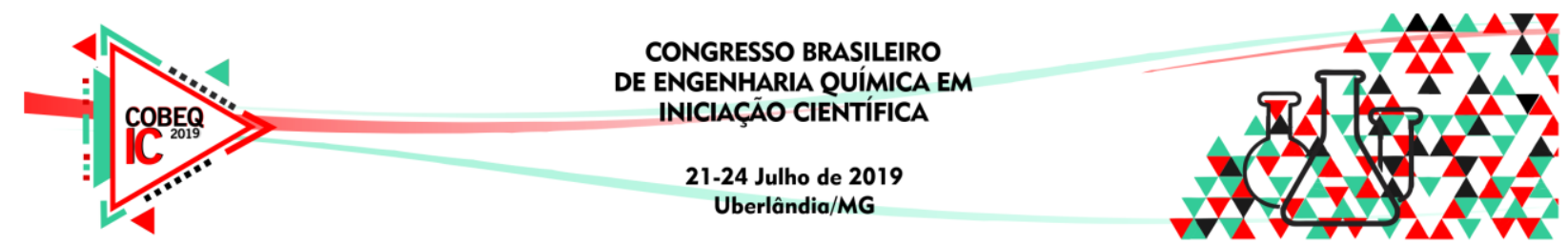

Figura 3 - Resultados ATG do bagaço e Whey Protein.
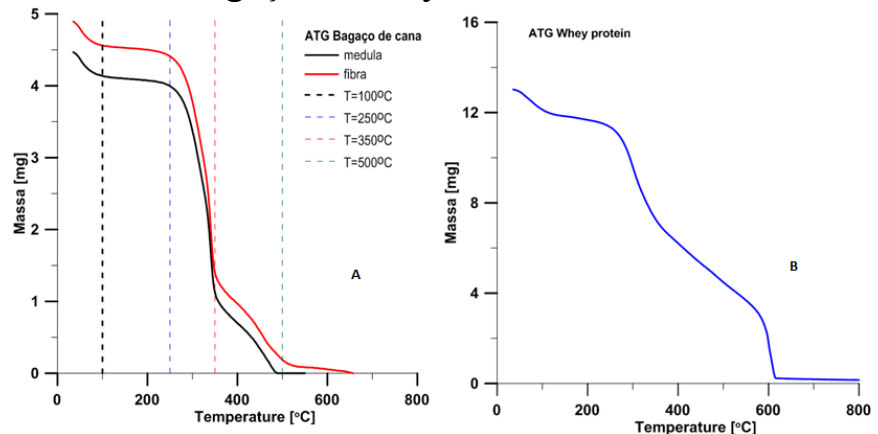

Os resultados observados para a decomposição térmica do bagaço está de acordo com estudo reportado por Ergfidenler and Ghaly (1995), que indicam que a decomposição de materiais lignocelulósicos ocorre em 3 faixas principais. A primeira faixa até $100^{\circ} \mathrm{C}$ está associada a perda de água, enquanto a segunda $\left(\right.$ de 250 a $\left.350^{\circ} \mathrm{C}\right)$ e terceira $\left(350^{\circ} \mathrm{C}\right.$ e $\left.500^{\circ} \mathrm{C}\right)$ estão associados à combustão de celulose/hemicelulose e lignina, respectivamente. Os resultados indicam ainda que o material fibroso apresenta maior teor de lignina que o material medular. A decomposição térmica do whey protein apresenta 4 principais regiões de perda de massa, a primeira até $100^{\circ} \mathrm{C}$ associada a perda de água, a segunda em $250^{\circ} \mathrm{C}$ até $350^{\circ} \mathrm{C}$, depois uma entre $350^{\circ} \mathrm{C}$ e $590^{\circ} \mathrm{C}$ e por fim uma acima $610^{\circ} \mathrm{C}$. Este resultado está em concordância com os valores reportados por Barreto et al. (2003) e Moldoveanu et al. (2013) para a decomposição térmica de proteínas do leite. A Figura 4 representa os resultados obtidos nos ensaios de adsorção utilizando a região medular e fibrosa do bagaço.

Figura 4 - Resultados ATG dos ensaios de adsorção utilizando a região medular e fibrosa.
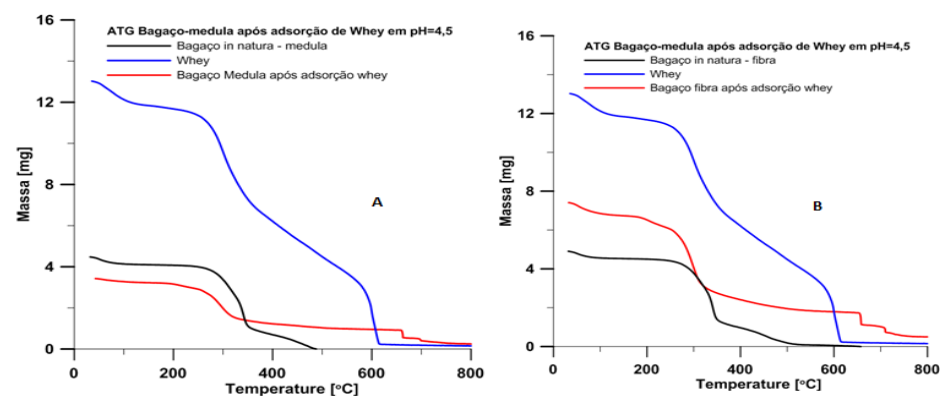

Podemos observar que houve uma mudança no perfil de perda de massa do bagaço após a adsorção, indicando que de fato houve adsorção de proteínas. Observa-se também que o bagaço após adsorção ainda sofre queima em temperatura superior a $600^{\circ} \mathrm{C}$, indicando que provavelmente as interações entre os sítios ativos do bagaço e da proteína são fortes.

\section{CONCLUSÕES}

Com base nos resultados mostrados pode-se concluir que a técnica de medir adsorção pela diferença de concentrações apresenta grande incerteza, isso se deve ao fato do adsorvente também adsorver água e a variabilidade da medida de absorbância. Também é possível observar que o $\mathrm{pH}$ da solução tem grande influência sobre a conformação das proteínas e 


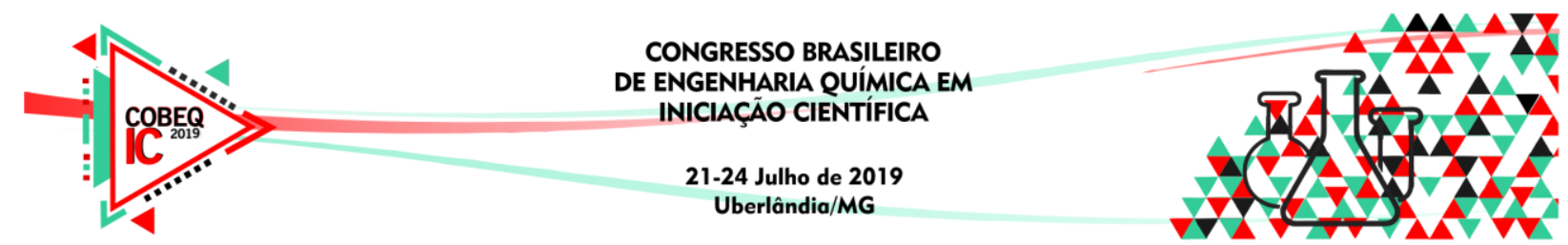

consequentemente sobre a adsorção. A técnica de ATG indica que o bagaço é capaz de adsorver proteínas entre os $\mathrm{pH}$ de 4 e 5,5.

\section{REFERÊNCIAS BIBLIOGRÁFICAS}

BARRETO, P. L. M.; PIRES, A.T.N.; SOLDI, V. Thermal Degradation of Edible Films Based on Milk Proteins and Gelatin in Inert Atmosphere Polymer Degradation and Stability, v. 79, p. 147-152, 2003.

BRADFORD, M. M. A Rapid and Sensitive Method for a Quantitation of Microgram Quantities of Proteins Utilizing the Principle of Protein - Dye Binding. Analytical Biochemistry, v. 72, p. 248-254, 1976.

ERGFINDELER, R, A, GHALY, A. E. Decomposition of Four Cereal Straws in Anoxidizing Atmosphere. BioTechnology, v. 50, p. 201-208, 1994.

FERREIRA, A. F., WATANABE, E. O.; ROMANIELO, L.L. Avaliação do Potencial Adsortivo do Bagaço de Cana na Adsorção de Proteínas do Leite. In: Anais do $12^{\circ}$ Encontro Brasileiro sobre Adsorção - EBA, Gramado, 2018.

MOHAN, T.; NIEGELHELL, K; SALOMÃO, C.; ZARTH, P; KARGL, R.; KÖSTLER, S.; RIBITSCH, V.; HEINZE, T.; SPIRK, S. AND STANA-KLEINSCHEK, K. Triggering Protein Adsorption on Tailored Cationic Cellulose Surfaces. Biomacromolecules, 2014.

MOLDOVEANU, C; ODOCHIAN, L.; PAIUS, C.M.; LORELA, I.; BAICEANU, A. Study on the Thermal Behavior of Casein in Air. Acta Chemica Iasi, v. 21, p. 31-46 (2013).

ZAIA, D. A. M.; ZAIA, C. T. B.; LICHTIG, J. Determinação de Proteínas Totais Via Espectofotometria: Vantagens e Desvantagens dos Métodos Existentes. Química Nova, 21, (6), 1998.

RUTHVEN, D.M. Principles of Adsorption and Adsorption Process. 1 ${ }^{\mathrm{a}}$. Ed. [S.1.]: John Wiley \& Sons, 1984. 